\title{
Recommended configuration for personal health records by standardized data item sets for diabetes mellitus and associated chronic diseases: a report from a collaborative initiative by six Japanese associations
}

\author{
Naoki Nakashima ${ }^{1} \cdot$ Mitsuhiko Noda $^{2} \cdot$ Kohjiro Ueki $^{3} \cdot$ Tatsuhiko Koga $^{4} \cdot$ Michio Hayashi $^{5} \cdot \mathrm{Katsuya} \mathrm{Yamazaki}^{6}$. \\ Tomoko Nakagami $^{7}$ - Makoto Ohara ${ }^{8}$ - Akira Gochi ${ }^{9}$ - Yasushi Matsumura ${ }^{10} \cdot$ Michio Kimura $^{11} \cdot$ Kazuhiko Ohe $^{12}$. \\ Dongchon Kang ${ }^{1} \cdot$ Yoshiyuki Toya $^{13} \cdot$ Kunihiro Yamagata $^{8} \cdot$ Koutaro Yokote $^{14} \cdot$ Shunya Ikeda $^{15} \cdot$ Naohiro Mitsutake $^{16}$. \\ Ryuichi Yamamoto ${ }^{17}$. Yukio Tanizawa ${ }^{18}$
}

Published online: 25 April 2019

(c) The Japan Diabetes Society 2019

\begin{abstract}
It is expected that a large amount of data related to diabetes and other chronic diseases will be generated. However, databases constructed without standardized data item sets can be limited in their usefulness. To address this, the Collaborative Committee of Clinical Informatization in Diabetes Mellitus was established in 2011 by the Japan Diabetes Society and Japan Association for Medical Informatics. The committee has developed core item sets and self-management item sets for diabetes mellitus, hypertension, dyslipidemia, and chronic kidney disease incollaboration with the Japanese Society of Hypertension, Japan Atherosclerosis Society, Japanese Society of Nephrology, and Japanese Society of Laboratory Medicine, as well as a mapping table that aligns the self-management item sets with the Japanese standardized codes for laboratory testing. The
\end{abstract}

The following authors are members of Japan Association for Medical Informatics: Naoki Nakashima, Makoto Ohara, Akira Gochi, Yasushi Matsumura, Michio Kimura, Kazuhiko Ohe. The following authors are members of Japan Diabetes Society: Mitsuhiko Noda, Kohjiro Ueki, Tatsuhiko Koga, Michio Hayashi, Katsuya Yamazaki, Tomoko Nakagami, Yukio Tanizawa. The following authors are members of Japanese Society of Laboratory Medicine: Dongchon Kang. The following authors are members of Japanese Society of Hypertension: Yoshiyuki Toya. The following authors are members of Japanese Society of Nephrology: Kunihiro Yamagata. The following authors are members of Japan Atherosclerosis Society: Koutaro Yokote.

The article is a report from the Collaborative Committee of Clinical Informatization in Diabetes Mellitus (by the Japan Diabetes Society and the Japan Association for Medical Informatics) with the Collaborative Initiative by additional four Japanese clinical associations (the Japanese Society of Laboratory Medicine, the Japanese Society of Hypertension, the Japanese Society of Nephrology and the Japan Atherosclerosis Society). The article has been jointly published in Diabetology International and Journal of Diabetes Investigation (https://doi.org/10.1111/ jdi.13043) by the Japan Diabetes Society.

Electronic supplementary material The online version of this article (https://doi.org/10.1007/s13340-019-00389-7) contains supplementary material, which is available to authorized users.

Extended author information available on the last page of the article 
committee also determined detailed specifications for implementing the four self-management item sets in personal health record applications to facilitate risk stratification, the generation of alerts using information and communications technology systems, the avoidance of data input errors, and the generation of reminders to input the self-management item set data. The approach developed by the committee may be useful for combining databases for various purposes (such as for clinical studies, patient education, and electronic medical record systems) and for facilitating collaboration between personal health record administrators.

Keywords Lifestyle related diseases $\cdot$ Core item sets $\cdot$ Personal health record

\section{Background and aims}

Many databases have been developed to store and generate information about diabetes mellitus and other chronic diseases [1,2], but their subsequent use can be limited by inconsistent data standards, such as the precise sets of data items used, and they may therefore have limited utility beyond their initially defined roles. Recently, there has been a rapid expansion of digitization in clinical practice and research. When appropriate information standards are defined before a new database is created, it may then be possible to reuse the database for other purposes. For example, a database developed for tracking information about patient self-monitoring of diabetes might then be used for clinical research, establishing evidence-based quality indicators, or facilitating regional medical cooperation.

In 2010, the Japan Diabetes Society (JDS) and the Japan Association for Medical Informatics (JAMI) established the Collaborative Committee for Clinical Informatization in Diabetes Mellitus (CCCIDM) to review the digitalization of clinical data about diabetes mellitus. The present article is a report of the work of the committee in collaboration with six Japanese academic associations: the JDS and JAMI, as well as the Japanese Society of Hypertension (JSH), the Japan Atherosclerosis Society (JAS), the Japanese Society of Nephrology (JSN), and the Japanese Society of Laboratory Medicine (JSLM, which participated from 2015). The report introduces the sets of data items established by the committee in 2015 for diabetes mellitus and the associated chronic diseases hypertension, dyslipidemia, and chronic kidney disease (CKD), as well as the committee's recommended data configurations, established in August 2018, for personal health record (PHR) applications, which was the first use of the data sets.

\section{Materials and methods}

By the end of 2011, CCCIDM developed a core data item set (CIS) that listed the minimum set of data items necessary for diabetes-related databases. However, the CIS alone could not be used in databases without additional data items. CCCIDM therefore proposed a self-management item set (SMIS), which may be useful for disease management by diabetic patients themselves based on the CIS developed by a working group sponsored by the Japanese Cabinet Secretariat and chaired by Professor Emeritus Naoko Tajima of Jikei University School of Medicine, who was also the first chairperson of the CCCIDM. Two other members of the CCCIDM also participated in the working group. The SMIS for diabetes was approved by the working group in 2012 and was subsequently approved by CCCIDM.

Because patients with diabetes often have other chronic diseases, it can be useful to combine data about diabetes mellitus with data about other chronic diseases. Therefore, in addition to diabetes mellitus, CCCIDM selected hypertension, dyslipidemia, and CKD for consideration because (1) they are associated with high rates of morbidity, (2) they are associated with considerable personal and socioeconomic burdens, (3) they are preventable through patient self-management, and (4) they can be evaluated and monitored using clear clinical parameters, such as blood testing and lifestyle monitoring. After selecting these diseases, CCCIDM invited the Japanese academic associations for each disease (JSH, JAS, and JSN) to form a collaborative extended committee (CEC) to establish consistent overlapping data item sets for all four diseases with the support of the Japanese Cabinet Secretariat. The SMISs for hypertension, dyslipidemia, and CKD were established in combination with the CISs in 2014 and were subsequently published on JAMI's website [3]. The CIS and SMIS for each disease were standardized in terms of data item name, granularity, and expression or unit used.

In 2015, the JSLM was included in the CEC. Since 2016, the CEC has collaborated with a PHR project entitled "Research on standardization and establishment of a business model for preventing the aggravation of lifestyle-related diseases, in cooperation with medical insurers, disease management companies, and medical institutions," administered by the Medical Information System Development Center (MEDIS-DC) and sponsored by the Japan Agency for Medical Research and Development (AMED). The aim of that project was to develop SMISs for implementation in PHR applications by mapping them to version 10 of the Japan 
Laboratory Analysis Codes (JLAC10) [4]. These codes are the Japanese standard for laboratory testing and can be mapped to logical observation identifier names and codes, which are international common terms (a set of identifiers, names, and codes) for identifying health measurements, observations, and documents [5]. The CEC subsequently determined the boundary values and thresholds for risk stratification, as well as values that could be used to provide smartphone alerts to various users, including patients, family members, and medical staff, based on standard clinical guidelines for the chronic diseases. The CEC also identified parameters that could be used to avoid data input errors and to prompt users to input data into the PHR within the appropriate time interval for each item.

\section{Results}

Between 2011 and 2014, the CEC established CISs and SMISs that included the CISs for each of the four chronic diseases and revised them in 2018 (Figs. 1 and 2). The CISs comprised 14 items for diabetes mellitus, 13 for hypertension, 13 for dyslipidemia, and 12 for CKD. By eliminating overlapping items, the overall number of CIS items was reduced from 52 to 23 (Fig. 2). The SMISs comprised 22 items for diabetes mellitus, 18 for hypertension, 15 for dyslipidemia, and 23 for CKD. After eliminating overlapping items, the total number of SMIS items was reduced from 78 to 41 (Fig. 2).

The four CISs and four SMISs were approved by the administrative boards of all six associations in 2015 (the first edition) and 2018 (the second edition). During 2016 and in August 2018, the CEC developed detailed specifications (Electronic supplementary materials 1-6) for implementing the four SMISs in PHR applications, described as "recommended configurations for the PHRs of chronic diseases." This was performed in collaboration with a PHR project by MEDIS-DC.

Because the standard clinical guidelines ask stricter indicators for patients with chronic diseases than for healthy people, the CEC determined a basic configuration for healthy people (Electronic supplementary material 1) and associated configurations for diabetes mellitus (Electronic supplementary material 2), hypertension (Electronic supplementary material 3), dyslipidemia (Electronic supplementary material 4), CKD (Electronic supplementary material 5), and coronary heart disease (Electronic supplementary material 6), which were added during a discussion by the $\mathrm{CEC}$ for risk assessment of the four chronic diseases. The tables show the various strict values for reminders, alerts, or thresholds for risk stratifications. PHR applications should use the basic configuration (Electronic supplementary

\begin{tabular}{|c|c|c|c|c|c|c|}
\hline ID of CIS & Item & Unit, expression & $\begin{array}{c}\text { CIS of diabetes } \\
\text { mellitus }\end{array}$ & $\begin{array}{c}\text { CIS of } \\
\text { hypertension }\end{array}$ & CIS of Dyslipidemia & CIS of CKD \\
\hline 1 & Height & $\mathrm{cm}$ & & & & \\
\hline 2 & Weight & $\mathrm{kg}$ & & & & \\
\hline 3 & Systolic Blood Pressure & $\mathrm{mmHg}$ & & & & \\
\hline 4 & Diastolic Blood Pressure & $\mathrm{mmHg}$ & & & & \\
\hline 5 & LDL Cholesterol & $\mathrm{mg} / \mathrm{dL}$ & & & & \\
\hline 6 & HDL Cholesterol & $\mathrm{mg} / \mathrm{dL}$ & & & & \\
\hline 7 & Smoking & Yes, No, Yes in the past & & & & \\
\hline 8 & Serum Creatinine & $\mathrm{mg} / \mathrm{dL}$ & & & & \\
\hline 9 & Urine Protein &,,,$- \pm+ 2+, 3+$ or over & & & & \\
\hline 10 & Blood Glucose & $\mathrm{mg} / \mathrm{dL}$ & & & & \\
\hline 11 & $\begin{array}{l}\text { Age diagnosed as Diabetes } \\
\text { Mellitus }\end{array}$ & $\begin{array}{l}\text { under } 10 y .0,10 \text { 's, 20's, , , 70's, } 80 y . \text { o. or over, Not yet, } \\
\text { Unknown }\end{array}$ & & & & \\
\hline 12 & HbA1c $※ 1$ & $\%$ & & & & \\
\hline 13 & ALT & $\mathrm{IU} / \mathrm{L}$ & & & & \\
\hline 14 & Diabetic Retinopathy & Yes, No, Unknown & & & & \\
\hline 15 & Age diagnosed as Hypertension & $\begin{array}{l}\text { under 10y.o, } 10 \text { 's, } 20 \text { 's, , , 70's, 80y.o. or over, Not yet, } \\
\text { Unknown }\end{array}$ & & & & \\
\hline 16 & Serum Potassium & $\mathrm{mEq} / \mathrm{L}$ & & & & \\
\hline 17 & Abnormality on ECG & Yes, No, Unknown & & & & \\
\hline 18 & Triglyceride & $\mathrm{mg} / \mathrm{dL}$ & & & & \\
\hline 19 & Age diagnosed as Dyslipidemia & $\begin{array}{l}\text { under } 10 y .0,10 \text { 's, } 20 \text { 's, , , 70's, } 80 \text { y.o. or over, Not yet, } \\
\text { Unknown }\end{array}$ & & & & \\
\hline 20 & Past History of Coronary Diseases & Yes (by contrast study), Yes (by another study), No, Unknown & & & & \\
\hline 21 & Age diagnosed as CKD & $\begin{array}{l}\text { under } 10 y .0,10 \text { 's, } 20 \text { 's, , , 70's, } 80 y .0 . \text { or over, Not yet, } \\
\text { Unknown }\end{array}$ & & & & \\
\hline 22 & Serum Albumin & $g / d L$ & & & & \\
\hline 23 & Hematuria &,,,$- \pm+ 2+, 3+$ or over (Micro hematuria), Macro hematuria & & & & \\
\hline
\end{tabular}

Fig. 1 Core item sets (CISs) for diabetes mellitus, hypertension, dyslipidemia, and chronic kidney disease (CKD) [3] 


\begin{tabular}{|c|c|c|c|c|c|c|c|c|c|c|c|c|c|c|}
\hline \multirow{2}{*}{\begin{tabular}{|l|} 
ID of \\
SMIS
\end{tabular}} & \multirow{2}{*}{ Item } & \multirow{2}{*}{ Unit, expression } & \multicolumn{3}{|c|}{ SMIS for Diabetes Mellitus } & \multicolumn{3}{|c|}{ SMIS for Hypertension } & \multicolumn{3}{|c|}{ SMIS for Dyslipidemia } & \multicolumn{3}{|c|}{ SMIS for CKD } \\
\hline & & & trom Molopal & 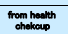 & trom home & from Mataleal & 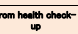 & from home & trom nestatal & 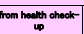 & from home & from Matabal & 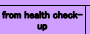 & from home \\
\hline 1 & Height & $\mathrm{cm}$ & 0 & o & & o & 0 & & 0 & 0 & & 0 & 0 & \\
\hline 2 & Weight & $\mathrm{kg}$ & 0 & 0 & & 0 & 0 & & o & 0 & & 0 & 0 & \\
\hline 3 & Systolic Blood Pressure & mmHg & 0 & 0 & & 0 & 0 & & 0 & 0 & & 0 & $\circ$ & \\
\hline 4 & Diastolic Blood Pressure & $\mathrm{mmHg}$ & 0 & ○ & & ○ & ○ & & ○ & $\circ$ & & 0 & $\circ$ & \\
\hline 5 & LDL Cholesterol & $\mathrm{mg} / \mathrm{dL}$ & 0 & o & & 0 & 0 & & $\circ$ & 0 & & o & o & \\
\hline 6 & HDL Cholesterol & $\mathrm{mg} / \mathrm{dL}$ & 0 & 0 & & 0 & 0 & & 0 & 0 & & 0 & 0 & \\
\hline 7 & Smoking & Yres, No, Yes in the past & 0 & 0 & & 0 & 0 & & 0 & 0 & & 0 & 0 & \\
\hline 8 & Serum Creatrinine & mg/da & 0 & & & $\circ$ & & & $\circ$ & & & $\circ$ & & \\
\hline 9 & Urine Protein &,,,$- \pm+ 2+, 3+$ or over & 0 & 0 & & 0 & 0 & & $\circ$ & 0 & & 0 & $\circ$ & \\
\hline${ }_{10}$ & Bliod Glucose & mg/dL & 0 & 0 & & ○ & 0 & & 0 & 0 & & & & \\
\hline${ }^{11}$ & Age diagnosed as Diabetes Mellitus & 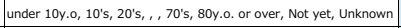 & $\circ$ & & & & & & & & & & & \\
\hline 12 & HbAic & $\%$ & 0 & $\circ$ & & & & & & & & 0 & $\circ$ & \\
\hline 13 & ALT & IV/L & 0 & 0 & & & & & o & o & & & & \\
\hline 14 & Diabetic Retinopathy & Yes, No, Unknown & 0 & & & & & & & & & & & \\
\hline 15 & Age diagnosed as Hypertension & under $10 y .0,10^{\prime} s, 200^{\prime}$, , , $70^{\prime s}, 80 y$. o. or over, No, Unknown & & & & o & & & & & & & & \\
\hline 16 & Serum Potassium & $\mathrm{mEq} / \mathrm{L}$ & & & & 0 & & & & & & 0 & & \\
\hline 17 & Abnormality on ECG & Yes, No, Unknown & & & & 0 & & & & & & & & \\
\hline 18 & Triglyceride & $\mathrm{mg} / \mathrm{dL}$ & 0 & 0 & & o & $\circ$ & & $\circ$ & 0 & & $\circ$ & 0 & \\
\hline 19 & \begin{tabular}{|l|l|} 
Age diagnosed as Dyslipidemia \\
\end{tabular} & under 10y.0, 10's, 20's, , , 70's, 80y.o. or over, No, Unknown & & & & & & & $\circ$ & & & & & \\
\hline 20 & Past History of Coronary Diseases & Yes (by contrasts study), Yes (by another study), No, Unknown & & & & & & & 0 & & & & & \\
\hline 21 & Age diagnosed as CKD & under 10y.o, 10's, 20's, , , 70's, 80y.o. or over, No, Unknown & & & & & & & & & & $\circ$ & & \\
\hline 22 & Serum Albumin & g/dL & & & & & & & & & & 0 & $\circ$ & \\
\hline 23 & Hematuria &,,,$- \pm+ 2+, 3+$ or over (Micro hematuria) , Macro hematuria & & & & & & & & & & 0 & 0 & \\
\hline 24 & Total Cholesterol & mg/dL & $\circ$ & & & o & & & o & & & $\circ$ & & \\
\hline 25 & Urine Albumin/Creatinine & $\mathrm{mg} / \mathrm{gcre}$ & 0 & & & & & & & & & & & \\
\hline 26 & AST & IU/L & 0 & 0 & & & & & & & & & & \\
\hline 27 & Waist & $\mathrm{cm}$ & & $\circ$ & & & 0 & & & 0 & & & & \\
\hline 28 & Urine Glucose &,,,$- \pm+ 2+$ or over & 0 & $\circ$ & & & & & & & & & & \\
\hline 29 & Y GTP & IU/L & 0 & o & & & & & & & & & & \\
\hline 30 & Diabetic neuropathy & Yes, No, Unknown & $\circ$ & & & & & & & & & & & \\
\hline 31 & Regular visit at Dental Clinic $(* 1)$ & Yes, No, Unknown & 0 & & & & & & & & & & & \\
\hline 32 & Uric Acid & mg/dL & & & & $\circ$ & & & & & & $\circ$ & $\circ$ & \\
\hline 33 & Systolic Blood Pressure at home & $\mathrm{mmHg}$ & & & & & & 0 & & & & & & \\
\hline 34 & Diastolic Blood Pressure at home & $\mathrm{mmHg}$ & & & & & & o & & & & & & \\
\hline 35 & Family History of Renal Failure( $(+2)$ & Yes, No, Unknown & & & & & & & & & & 0 & & \\
\hline 36 & Urine Protetin /Creatinine & g/gcre & & & & & & & & & & o & o & \\
\hline 37 & Urine Protein / Day & g/day & & & & & & & & & & 0 & 0 & \\
\hline 38 & Serum Total Protein & g/dLL & & & & & & & & & & 0 & 0 & \\
\hline 39 & BUN & mg/dL & & & & & & & & & & 0 & & \\
\hline 40 & Hemoglobin & g/dL & & & & & & & & & & 0 & 0 & \\
\hline 41 & Costatin C & $\mathrm{mg} / \mathrm{L}$ & & & & & & & & & & $\circ$ & & \\
\hline
\end{tabular}

Fig. 2 The self-management item sets (SMISs) [3]. Notes: $(* 1)$ Regular visits to a dental clinic (at least once per year). (*2) A family history of renal failure, including hemodialysis, renal transplantation, or renal failure in a family member of $\leq 2$ degrees of separation

material 1) to detect the possibility of pre-diseases (yellow) or the onset of diseases (orange and red) when the user does not have any previously diagnosed diseases. And it should use the additional configuration for the appropriate chronic disease to know the risk of serious complications of the diseases (green; minimum risk, yellow; light risk, orange; moderate risk, red; high risk) when the patient experiences the onset of the disease (Electronic supplementary materials 2-6). If the PHR has various configurations because the patient suffers from more than one of the chronic diseases, the strictest configuration should be used.

The CEC defined fasting and non-fasting conditions for the configuration of PHRs for chronic diseases. The fasting condition follows fasting for $10 \mathrm{~h}$ (although the consumption of water and non-calorie tea is acceptable). The values for alerts and risk stratification in the configuration of the PHR refer to fasting condition results for the tests for blood glucose (SMIS-ID 10 in Fig. 2), triglycerides (SMIS-ID 18), urine glucose (SMIS-ID 28), and self-monitored blood glucose (no ID). The CEC recommends that PHR applications include a function to identify whether these four items have been measured under the fasting condition.

The SMIS and recommended PHR configuration have several lipid-related indicators, including levels of lowdensity lipoprotein (LDL) cholesterol (by direct assay), total cholesterol, high-density lipoprotein (HDL) cholesterol, and triglycerides. Additional indicators, such as LDL cholesterol by the Friedewald formula and non-HDL cholesterol, can be calculated from data in the SMIS. However, serum triglyceride levels are affected by eating, and some indicators are unstable in blood samples with high triglyceride levels. Thus, the JAS Guidelines for Prevention of Atherosclerotic Cardiovascular Diseases 2017 [6] has specified the following according to triglyceride levels: when the triglyceride level is $<400 \mathrm{mg} / \mathrm{dL}$, LDL cholesterol by the Friedewald formula (only in the fasting condition) or direct assay, or non-HDL-cholesterol, should be used for the evaluation; when the triglyceride level is in the range $400-600 \mathrm{mg} / \mathrm{dL}$, 
Table 1 Mapping similarities between the self-management item set and the Japan Laboratory Analysis Code version 10 (JLAC10)

\begin{tabular}{|c|c|c|c|c|}
\hline$\#$ & Item name & Expression/unit & JLAC10 code & Supplement \\
\hline 1 & Height & $\mathrm{cm}$ & 9N001000000000001 & \\
\hline 2 & Weight & $\mathrm{kg}$ & 9N006000000000001 & \\
\hline 3 & Systolic blood pressure & $\mathrm{mmHg}$ & 9A751000000000001 & \\
\hline 4 & Diastolic blood pressure & $\mathrm{mmHg}$ & 9A761000000000001 & \\
\hline \multirow[t]{2}{*}{5} & \multirow[t]{2}{*}{ LDL-cholesterol } & \multirow[t]{2}{*}{$\mathrm{mg} / \mathrm{dL}$} & 3F077000002327101 & \\
\hline & & & 3F077000002391901 & \multirow[t]{4}{*}{ Friedewald } \\
\hline 6 & HDL-cholesterol & $\mathrm{mg} / \mathrm{dL}$ & 3F070000002327101 & \\
\hline 7 & Smoking & Yes, no, yes in the past & 9N736000000000011 & \\
\hline 8 & Serum creatinine & $\mathrm{mg} / \mathrm{dL}$ & 3C015000002327101 & \\
\hline 9 & Urine protein &,,,$- \pm+ 2+, 3+$ or over & 1A990000000190153 & Urinary test strip method \\
\hline 10 & Blood glucose & $\mathrm{mg} / \mathrm{dL}$ & $3 \mathrm{D} 010 * * * * 01927201$ & $\mathrm{NaF}$, plasma \\
\hline 11 & Age diagnosed with diabetes mellitus & $\begin{array}{l}\text { Less than } 10 \text { years old, } 10 \mathrm{~s}, 20 \mathrm{~s}, \ldots, 70 \mathrm{~s}, \\
80 \text { years old or over, unknown }\end{array}$ & 9N041000000000011 & \\
\hline 12 & HbA1c (NGSP) & $\%$ & 3D046000001920402 & \\
\hline 13 & ALT & $\mathrm{IU} / \mathrm{L}$ & 3В045000002327201 & \\
\hline 14 & Diabetic retinopathy & Yes, no, unknown & 9N042000000000011 & \\
\hline 15 & Age diagnosed with hypertension & $\begin{array}{l}\text { Less than } 10 \text { years old, } 10 \mathrm{~s}, 20 \mathrm{~s}, \ldots 70 \mathrm{~s} \text {, } \\
80 \text { years old or over, unknown }\end{array}$ & 9N043000000000011 & \\
\hline 16 & Serum potassium & $\mathrm{mEq} / \mathrm{L}$ & $3 \mathrm{H} 015000002326101$ & \\
\hline 17 & Abnormality on ECG & Yes, no, unknown & 9A110160700000011 & \\
\hline 18 & Triglyceride & $\mathrm{mg} / \mathrm{dL}$ & $3 \mathrm{~F} 0150 * * * * 2327101$ & \\
\hline 19 & Age diagnosed with dyslipidemia & $\begin{array}{l}\text { Less than } 10 \text { years old, } 10 \mathrm{~s}, 20 \mathrm{~s}, \ldots 70 \mathrm{~s} \text {, } \\
80 \text { years old or over, unknown }\end{array}$ & 9N044000000000011 & \\
\hline 20 & Past history of coronary diseases & $\begin{array}{l}\text { Yes (by contrast study), yes (by another } \\
\text { study), no, unknown }\end{array}$ & 9N721000000000011 & \\
\hline 21 & Age diagnosed with CKD & $\begin{array}{l}\text { Less than } 10 \text { years old, } 10 \mathrm{~s}, 20 \mathrm{~s}, \ldots 70 \mathrm{~s} \text {, } \\
80 \text { years old or over, unknown }\end{array}$ & 9N045000000000011 & \\
\hline 22 & Serum albumin & $\mathrm{g} / \mathrm{dL}$ & $3 \mathrm{~A} 015000002327101$ & \\
\hline 23 & Hematuria & $\begin{array}{l}-, \pm,+, 2+, 3+\text { or over (micro hematu- } \\
\text { ria), macrohematuria }\end{array}$ & 1A990000000190159 & Urinary test strip method \\
\hline \multirow[t]{2}{*}{24} & Total cholesterol & $\mathrm{mg} / \mathrm{dL}$ & $3 F 050000002327101$ & \\
\hline & Non-HDL-cholesterol & $\mathrm{mg} / \mathrm{dL}$ & 3F069000002391901 & \\
\hline 25 & Urine albumin/creatinine & $\mathrm{mg} / \mathrm{gCr}$ & 3A015000000106128 & \\
\hline 26 & AST & $\mathrm{IU} / \mathrm{L}$ & 3В035000002327201 & \\
\hline 27 & Waist & $\mathrm{cm}$ & 9N016160100000001 & \\
\hline \multirow[t]{2}{*}{28} & \multirow[t]{2}{*}{ Urine glucose } & \multirow[t]{2}{*}{,,,$- \pm+ 2+$ or over } & $1 \mathrm{~A} 990 * * * * 00190154$ & \multirow{2}{*}{$\begin{array}{l}\text { Urinary test strip method } \\
\text { Specific health checkup code }\end{array}$} \\
\hline & & & $1 \mathrm{~A} 020 * * * * 00190111$ & \\
\hline 29 & $\gamma-\mathrm{GTP}$ & $\mathrm{IU} / \mathrm{L}$ & 3В090000002327101 & \\
\hline 30 & Diabetic neuropathy & Yes, no, unknown & 9N046000000000011 & \\
\hline 31 & Regular visit at dental clinic & Yes, no, unknown & 9N531000000000011 & \\
\hline 32 & Uric acid & $\mathrm{mg} / \mathrm{dL}$ & $3 \mathrm{C} 020000002327101$ & \\
\hline 33 & Systolic blood pressure at home & $\mathrm{mmHg}$ & 9A751000000099501 & \\
\hline 34 & Diastolic blood pressure at home & $\mathrm{mmHg}$ & 9A761000000099501 & \\
\hline 35 & Family history of renal failure & Yes, no, unknown & 9N047000000000011 & \\
\hline 36 & Urine protein/creatinine & $\mathrm{g} / \mathrm{gCr}$ & $1 \mathrm{~A} 015000000127128$ & \\
\hline 37 & Urine protein/day & g/day & $1 \mathrm{~A} 015000000427126$ & \\
\hline 38 & Serum total protein & $\mathrm{g} / \mathrm{dL}$ & $3 \mathrm{~A} 010000002327101$ & \\
\hline 39 & BUN & $\mathrm{mg} / \mathrm{dL}$ & $3 \mathrm{C} 025000002327201$ & \\
\hline \multirow[t]{2}{*}{40} & \multirow[t]{2}{*}{ Hemoglobin } & \multirow[t]{2}{*}{$\mathrm{g} / \mathrm{dL}$} & 2A990000001930953 & \\
\hline & & & 2A030000001930901 & Specific health checkup code \\
\hline 41 & Cystatin C & $\mathrm{mg} / \mathrm{L}$ & 3C016000002306201 & \\
\hline Extra items & Weight at home & $\mathrm{Kg}$ & 9N006000000099401 & \\
\hline Extra items & Self-monitoring blood glucose & $\mathrm{mg} / \mathrm{dL}$ & $3 \mathrm{D} 010 * * * * 01899101$ & \\
\hline
\end{tabular}

****[1288: before breakfast, 1289: after breakfast, 1290: before lunch, 1291: after lunch, 1292: before supper, 1293: after supper, 1299: casual, 1300: fasting] 
Table 2 Outline time table of implementation using the self-management item set (SMIS) and the recommended configuration for personal health records (PHRs)

\begin{tabular}{|c|c|c|c|c|c|c|}
\hline & Startup & Diabetes SMIS & $\begin{array}{l}\text { Hypertension } \\
\text { SMIS }\end{array}$ & $\begin{array}{l}\text { Dyslipidemia } \\
\text { SMIS }\end{array}$ & CKD SMIS & Specification for PHR \\
\hline \multicolumn{7}{|l|}{ Case registration cohort } \\
\hline J-DREAMS & 2015 & (0) & - & - & - & - \\
\hline J-CKD-DB & 2015 & - & - & - & 0 & - \\
\hline J-DOME & 2016 & (0) & ○) & (0) & (0) & - \\
\hline \multicolumn{7}{|l|}{ PHR project } \\
\hline PHR (by MEDIS-DC) & 2016 & (0) & () & () & (0) & () \\
\hline PHR (DialBetics) & 2018 ? & O(planned) & - & - & O(planned) & O(planned) \\
\hline
\end{tabular}

Note: @ Full implementation, $\bigcirc$ Partial implementation

LDL cholesterol (by direct assay but not by the Friedewald formula) or non-HDL-cholesterol should be used for the evaluation; for triglyceride levels in the range $600-1000 \mathrm{mg} /$ $\mathrm{dL}$, LDL cholesterol by direct assay, but not by the Friedewald formula, should be used for the evaluation; and when triglycerides $\geq 1000 \mathrm{mg} / \mathrm{dL}$, triglyceride should be improved before the evaluation of lipid-related indicators.

The JSLM subsequently mapped the SMISs to the JLAC10 (Table 1), and this map was approved by the CEC in 2018. Mapping the SMISs to JLAC10 is complicated because it depends on factors, such as the assay methods and reagents used. Therefore, when PHR providers install actual JLAC10 codes in the system, they should be careful and ensure they use the correct codes.

\section{Discussion}

"Big data" has evolved to incorporate clinical information, and it is expected that a vast amount of diabetes-related data will be generated. It is therefore important to develop and implement standardized data item sets for diabetes-related databases. Linking those databases to databases for other chronic diseases should help generate useful, high-quality data. However, attempts to standardize data item sets have often failed because of an excessive number of items. In our approach, we defined the CIS for each disease and then developed SMISs based on those CISs to minimize the number of items.

Our SMISs have been used in databases for three large disease registry studies (Table 2). For example, the Japan Diabetes Comprehensive Database Project Based on an Advanced Electronic Medical Record System (J-DREAMS), administered by the National Center for Global Health and Medicine and the JDS, used all of our SMIS items for diabetes mellitus [7, 8]. In addition, J-CDK-DB [9], administered by the JSN, used some of the CKD SMIS items, which can be automatically output from the SS-MIX2 system [10], and the Japan Medical Association Diabetes Database of Clinical Medicine (J-DOME), administered by the Japan Medical Association to collect clinical information about diabetes, used all of our SMIS items for all four chronic diseases [11].

We implemented all the SMIS items for the four chronic diseases with detailed specifications for their inclusion in a PHR application that is being developed as part of the MEDIS-DC project, funded by AMED. We are also conducting verification studies in the cities of Nishinomiya (Hyogo Prefecture), Taku (Saga Prefecture), and Koriyama (Fukushima Prefecture). Finally, another PHR project, "Expanding and strengthening cooperation of a CKD database and establishment of a comprehensive database," initiated in 2017 and also funded by AMED, is using our diabetes-related SMIS items in the "DialBetics" PHR application [12].

\section{Conclusions}

In conclusion, CCCIDM and the CEC established standardized CISs and SMISs for the four chronic diseases. They also developed specifications for implementing these items in PHR applications, such as identifying values for risk stratification, generating alerts using information and communications technology systems, avoiding data input errors, and generating reminders to input the SIMS data. In addition, a table was developed to map the item sets to the JLAC10 codes.

Acknowledgements We thank the former members of the CCCIDM, including Professor Emeritus Naoko Tajima, Dr. Shinji Kagimoto, Prof. Shinsuke Fujita, Prof. Syunji Wakamiya, and Prof. Masaki Miyamoto for their contributions to establishing the CISs and SMISs. We also thank the six participating associations (JDS, JAMI, JSH, JAS, JSN, and JSLM) and observers from the associations, and the offices of the JDS and JAMI for supporting the CCCIDM and CEC activities. We appreciate the consistent support by the Japanese Cabinet Secretariat in developing SMISs through the CEC meeting. Furthermore, we thank the MEDIS-DC for supporting the CEC meeting as part of the "Research project on standardization and establishment of a business 
model for preventing aggravation of lifestyle-related diseases in cooperation with the medical insurers, disease management companies, and medical institutions," which is funded by AMED.

\section{Compliance with ethical standards}

Conflict of interest Naoki Nakashima has received research grants from Fujitsu Ltd. Kohjiro Ueki has received honoraria for lectures from Astellas Pharma Inc., AstraZeneca Co., Ltd., Daiichi Sankyo Co. Ltd., Eli Lilly Japan Co. Ltd., Kyowa Hakko Kirin Co. Ltd., Mitsubishi Tanabe Co. Ltd., MSD Co. Ltd., Nippon Boehringer Ingelheim Co. Ltd., Novo Nordisk Pharma Ltd., Ono Pharmaceutical Co. Ltd, Sanofi Aventis Co. Ltd, Shionogi \& Co. Ltd., Sumitomo Dainippon Co. Ltd, Taisho Toyama Pharmaceutical Co. Ltd., and Takeda Pharmaceutical Co Ltd., and research grants from Astellas Pharma Inc. He has also received scholarship grants from Astellas Pharma Inc, Daiichi Sankyo Co. Ltd., Eli Lilly Japan Co. Ltd., Kowa Co. Ltd., Kyowa Hakko Kirin Co. Ltd., Mitsubishi Tanabe Co. Ltd., Nippon Boehringer Ingelheim Co. Ltd., Novartis Pharma Co. Ltd., Novo Nordisk Pharma Ltd., Ono Pharmaceutical Co. Ltd., Sanofi Aventis Co. Ltd., Sumitomo Dainippon Co. Ltd., Taisho Toyama Pharmaceutical Co. Ltd., and Takeda Pharmaceutical Co Ltd. Koutaro Yokote has received honoraria for lectures from Astellas Pharma Inc., Astellas Amgen BioPharma Co. Ltd., AstraZeneca Co., Ltd., MSD Co. Ltd., Ono Pharmaceutical Co. Ltd., Sanwa Kagaku Kenkyusho Co. Ltd., Kyowa Hakko Kirin Co. Ltd., Kowa Co. Ltd., Kowa Pharmaceutical Co., Ltd, Sanofi Aventis Co. Ltd., Shionogi \& Co. Ltd., Taisho Toyama Pharmaceutical Co. Ltd., Takeda Pharmaceutical Co Ltd., Mitsubishi Tanabe Co. Ltd., Daiichi Sankyo Co. Ltd., Sumitomo Dainippon Co. Ltd., Eli Lilly Japan Co. Ltd., Nippon Boehringer Ingelheim Co. Ltd., Novartis Pharma Co. Ltd., Novo Nordisk Pharma Ltd., Pfizer Japan Inc., and Mochida Pharmaceutical Co. Ltd., and research grants from Astellas Pharma Inc. He has also received scholarship grants from Astellas Pharma Inc., MSD Co. Ltd., Ono Pharmaceutical Co. Ltd., Shionogi \& Co. Ltd., Kyowa Hakko Kirin Co. Ltd., Taisho Toyama Pharmaceutical Co. Ltd., Takeda Pharmaceutical Co. Ltd., Mitsubishi Tanabe Co. Ltd., Teijin Pharm Ltd., Daiichi Sankyo Co. Ltd., Sumitomo Dainippon Co. Ltd., Eli Lilly Japan Co. Ltd., Nippon Boehringer Ingelheim Co. Ltd., Novo Nordisk Pharma Ltd., Pfizer Japan Inc., and Mochida Pharmaceutical Co. Ltd., and a course endowed by MSD Co. Ltd. Mitsuhiko Noda, Tatsuhiko Koga, Michio Hayashi, Katsuya Yamazaki, Tomoko Nakagami, Makoto Ohara, Akira Gochi, Yasushi Matsumura, Michio Kimura, Kazuhiko Ohe, Dongchon Kang, Yoshiyuki Toya, Kunihiro Yamagata, Shunya Ikeda, Naohiro Mitsutake, Ryuichi Yamamoto, and Yukio Tanizawa have no conflict of interest.

Ethical standards There are no ethical issues associated with this report.

\section{References}

1. Kobayashi M, Yamazaki K, Hirao K, Oishi M, Kanatsuka A, Yamauchi M, Takagi H, Kawai K, Japan Diabetes Clinical Data Management Study Group. The status of diabetes control and antidiabetic drug therapy in Japan-a cross-sectional survey of
17,000 patients with diabetes mellitus (JDDM 1). Diabetes Res Clin Pract. 2006;73:198-204.

2. Hayashino Y, Izumi K, Okamura S, Nishimura R, Origasa $H$, Tajima N, JDCP Study Group. Duration of diabetes and types of diabetes therapy in Japanese patients with type 2 diabetes: The Japan Diabetes Complication and its Prevention prospective study 3 (JDCP study 3). J Diabetes Investig. 2017;8:243-9.

3. Japan Association for Medical Informatics. Minimum Sets of Data Elements for Four Lifestyle-related Diseases and Recommended Configuration for Personal Health Records 2018. http://jami.jp/ medicalFields/2018Oct23.php. Accessed Feb 2019 (Japanese only).

4. Kimura M, Kanno T, Tani S, Satomura Y. Standardizations of clinical laboratory examinations in Japan. Int J Med Inform. 1998;48:239-46.

5. Forrey AW, McDonald CJ, DeMoor G, Huff SM, Leavelle D, Leland D, Fiers T, Charles L, Griffin B, Stalling F, Tullis A, Hutchins K, Baenziger J. Logical observation identifier names and codes (LOINC) database: a public use set of codes and names for electronic reporting of clinical laboratory test results. Clin Chem. 1996;42:81-90.

6. Kinoshita M, Yokote K, Arai H, Iida M, Ishigaki Y, Ishibashi S, Umemoto S, Egusa G, Ohmura H, Okamura T, Kihara S, Koba S, Saito I, Shoji T, Daida H, Tsukamoto K, Deguchi J, Dohi S, Dobashi K, Hamaguchi H, Hara M, Hiro T, Biro S, Fujioka Y, Maruyama C, Miyamoto Y, Murakami Y, Yokode M, Yoshida H, Rakugi H, Wakatsuki A, Yamashita S. Committee for Epidemiology and Clinical Management of Atherosclerosis. Japan Atherosclerosis Society (JAS) Guidelines for Prevention of Atherosclerotic Cardiovascular Diseases 2017. J Atheroscler Thromb. 2018; 25(9):846-984.

7. Sugiyama T, Miyo K, Tsujimoto T, Kominami R, Ohtsu H, Ohsugi M, Waki K, Noguchi T, Ohe K, Kadowaki T, Kasuga M. Design of and rationale for the Japan Diabetes compREhensive database project based on an Advanced electronic Medical record System (J-DREAMS). Diabetol Int. 2017;8:375-82.

8. J-DREAMS database (in Japanese). 2018. http://jdreams.jp/. Accessed Feb 2019.

9. J-CKD-DB database. 2018. http://j-ckd-db.sakura.ne.jp/english/ index.html. Accessed Aug 2018.

10. Kimura M, Nakayasu K, Ohshima Y, Fujita N, Nakashima N, Jozaki H, Numano T, Shimizu T, Shimomura M, Sasaki F, Fujiki T, Nakashima T, Toyoda K, Hoshi H, Sakusabe T, Naito Y, Kawaguchi K, Watanabe H, Tani S. SS-MIX: a ministry project to promote standardized healthcare information exchange. Methods Inf Med. 2011;50:131-9.

11. J-DOME database (in Japanese). 2018. http://jdome.jmari.med. or.jp/. Accessed Aug 2018.

12. Waki K, Fujita H, Uchimura Y, Omae K, Aramaki E, Kato S, Lee H, Kobayashi H, Kadowaki T, Ohe K. DialBetics: a novel smartphone-based self-management support system for type 2 diabetes patients. J Diabetes Sci Technol. 2014;8:209-15.

Publisher's Note Springer Nature remains neutral with regard to jurisdictional claims in published maps and institutional affiliations. 


\section{Affiliations}

\section{Naoki Nakashima ${ }^{1} \cdot$ Mitsuhiko Noda $^{2} \cdot K$ Kohjiro Ueki ${ }^{3} \cdot$ Tatsuhiko Koga $^{4} \cdot$ Michio Hayashi $^{5} \cdot$ Katsuya Yamazaki $^{6}$. Tomoko Nakagami ${ }^{7} \cdot$ Makoto Ohara $^{8} \cdot$ Akira Gochi $^{9}$. Yasushi Matsumura ${ }^{10} \cdot$ Michio Kimura $^{11} \cdot$ Kazuhiko Ohe $^{12}$. Dongchon Kang ${ }^{1} \cdot$ Yoshiyuki Toya $^{13} \cdot$ Kunihiro Yamagata $^{8} \cdot$ Koutaro Yokote $^{14} \cdot$ Shunya Ikeda $^{15} \cdot$ Naohiro Mitsutake ${ }^{16}$. Ryuichi Yamamoto ${ }^{17} \cdot$ Yukio Tanizawa ${ }^{18}$}

Naoki Nakashima

nnaoki@info.med.kyushu-u.ac.jp

1 Medical Information Center, Kyushu University Hospital, 3-1-1 Maidashi, Higashi-ku, Fukuoka 812-8582, Japan

2 Saitama Medical University, Saitama, Japan

3 National Center for Global Health and Medicine, Tokyo, Japan

4 Hara Doi Hospital, Fukuoka, Japan

5 NTT Medical Center Tokyo, Tokyo, Japan

6 Tsukuba Diabetic Center Kawai Clinic, Ibaraki, Japan

7 Tokyo Women's Medical University, Tokyo, Japan

8 University of Tsukuba, Ibaraki, Japan

9 Ibara City Hospital, Okayama, Japan
10 Osaka University, Osaka, Japan

11 Hamamatsu University School of Medicine, Shizuoka, Japan

12 University of Tokyo, Tokyo, Japan

13 Yokohama City University, Kanagawa, Japan

14 Chiba University, Chiba, Japan

15 International University of Health and Welfare, Chiba, Japan

16 Institute for Health Economics and Policy, Tokyo, Japan

17 Medical Information System Development Center, Tokyo, Japan

18 Yamaguchi University, Yamaguchi, Japan 